\title{
Intelligent Low-Cost Micro-Hydro Power Emulator for Domestic Applications
}

\author{
Salma A. S. Alarefi *, Member,IEEE \\ School of Computer Science and Electronic Engineering \\ CSEE, University of Essex \\ Colchester, UK \\ sasalaa@essex.ac.uk
}

\author{
Stuart D. Walker \\ School of Computer Science and Electronic Engineering \\ CSEE, University of Essex \\ Colchester, UK \\ stuwal@essex.ac.uk
}

\begin{abstract}
Microgeneration of hydropower for domestic applications is emerging as a promising technology. However, the amount of energy that can be harvested is still modest. The lack of experimental evaluation systems which emulate the power characteristics of such generators for professional development and research has challenged the growth of micro-hydropower generation. This paper describes a laboratory micro-hydropower emulator for research purposes. The core novelty of the system lies in the use of a $2 \times 2$ serial/parallel combination of micro-hydro generators. The system features hydro generation with electronically-controllable water flow rates and allows emulation of different household usages.
\end{abstract}

Keywords- Microgenration; hydropower; professional development; research; power emulator

\section{INTRODUCTION}

Harvesting energy from water has existed since early history. However, the fact that convenient water streams and rivers cannot be found in the urban environment along with concerns about the environmental damage building dams can cause, has challenged hydroelectric generation. Nevertheless, a typical U.K. household uses a significant 150 liters of water per person per day [1]. This amount of water can be used to produce electricity from the water flowing inside the domestic pipelines. Unlike other approaches of hydroelectric generation which cannot be easily integrated in urban environment, every house has a water tap. If micro-hydropower generators are embedded inside every house's water supply, a useful amount of energy can be generated. However, there are many challenges in harnessing such small but valuable power from the water supply.

The basic idea of harnessing power from water supply is to use the velocity or force (kinetic energy) of water flow to turn the micro turbine and generate electricity. The amount of power that can be generated depends on the water flow rate, water consumption, pressure as well as the generator [2]. Whereas, the water consumption depends on the amount of water consumed every day, the flow rate is determined by the head pressure from the reservoir where the height between water intake and the turbine is the pressure head [3].
A number of in-line hydro generators for domestic water pipes have been patented [4] [5] [6]. The efficiency of the turbine however, is the major challenge in harnessing such minute amount of energy. At the maximum water force, power of 0.5 to 0.75 watts is harnessed from a mini fan inserted inside a water tap in [7]. A hydropower harvester for smart metering application in [8], with a threshold flow rate of $3 \mathrm{r} / \mathrm{min}$, reported to generate an output in the range from $15 \mathrm{~mW}$ at 5 $\mathrm{l} / \mathrm{min}$ to $720 \mathrm{~mW}$ at $20 \mathrm{l} / \mathrm{m}$ (fully opened tap water). A novel inline hydropower system for power generation from water pipelines is being developed in Hong Kong [9]. The system proposes embedding small turbines into water pipes to generate electricity. The proposed micro- turbine is claimed to generate up to 80 volts enough to power a fluorescent bulb. Integrating an array of the small turbines in the drinking water pipelines is believed to save $700 \mathrm{kWh}$ of electricity and reduce $560 \mathrm{~kg}$ of carbon dioxide emission per year [9].

A variety of low power applications have deployed microgenerators to scavenge energy from water running through pipelines. Hydro powered smart sensors for faucet and flush are commercially available in [10], where a micro generator is used to generate electric current from water flow and store it in rechargeable cells. An award for the ES pipe Waterwheel which harnesses regular water tap flow to power specialized bulbs was granted the 2012 International Design Excellence Awards IDEA [11]. The motive of the invention was intended for use in developing countries which suffer severe power shortages. Hydropower generation could be a very promising renewable energy source if efficient generators are used. The low output could be enhanced using a set of hydro turbines to be then used for low power applications.

Further, the growing concern with global energy shortages along with the associated environmental issues has sparked a great interest in microgenration of renewable energy such as hydropower. This among other factors has necessitated the need for experimental evaluation systems that could emulate the power characteristics of such generators for professional formation and research. Thus, this paper proposes a hydropower demonstrator for laboratory investigations that incorporates combination turbines run in series/parallel. 


\section{APPROACH AND METHOD}

Domestic water taps pose a physical challenge due to their size. Also the amount of potential energy it offers is negligible when compared to a dam or a hydro electrical plant. However, if a combination of turbines is used, the generated power can be enhanced.

\section{A. Flow Rate and Head Pressure}

The amount of generated power is directly related to the water flow rate and pressure head. Thus, the higher the water flow rate and pressure head, the more the kinetic energy which is needed to rotate the blades of the turbine. The generator will then start moving converting the kinetic energy to electrical energy.

Water pressure is the force that drives water through pipes and determines the water flow. To avoid water waste or flood, water from supply goes through pressure reducing valves. In the U.K. , consistent with the guaranteed standards scheme (GSS) the minimum water pressure in the communication pipe a water supply can provide is seven meters static head $(0.7$ bars). According to the water service regulation authority OFWAT, the standard measure (DG2) for water pressure is ten meters head of pressure (flow rate of 9 liters per minute) [2].

The generated power increases with increasing water consumption. However, it is a waste of resources to increase the amount of power generated by running the water for longer. Water flow rate is the amount of water that passes through a given surface per time unit. The water flow rate $Q$ in cubic meters per second $\left(\mathrm{m}^{3} / \mathrm{s}\right)$, for water passing through surface with area of $A$ in square meters $\left(\mathrm{m}^{2}\right)$ with flow velocity $v$ in meters per second $(\mathrm{m} / \mathrm{s})$ is given by:

$$
Q=A \cdot v
$$

\section{B. Design and Construction}

Mechanically, the complete system of the hydropower emulator consists of two lightweight wooden frames and a plastic water tank. The 20 liter water tank is placed on a wooden frame base with four castors making it easy to move the emulator. A square wooden frame is placed on the mobile wooden base and surrounds the base of the water tank, to secure the water tank to the wooden base. A pump is used to drive flow to and from the water tank, and a water tap attached of the progressive shut-off type found in households

A light weight wooden frame which has a truncated pyramid shape is mounted on top of the water tank. . The truncated body is secured to the tank using a wooden strip on both sides of the frame. Two opposite sides of the truncated body are left open allowing space for measurement desk. A diagram of the mechanical design of the hydro emulator is shown in Figure 1

The control circuit is placed on the top of the truncated pyramid body. It includes a power speed controller and electronic switch. The power speed controller controls the speed of the water pump placed inside the water tank. The electronic switch is computer-controlled though USB to emulate different loads (i.e. washing machine, shower tap. etc.).

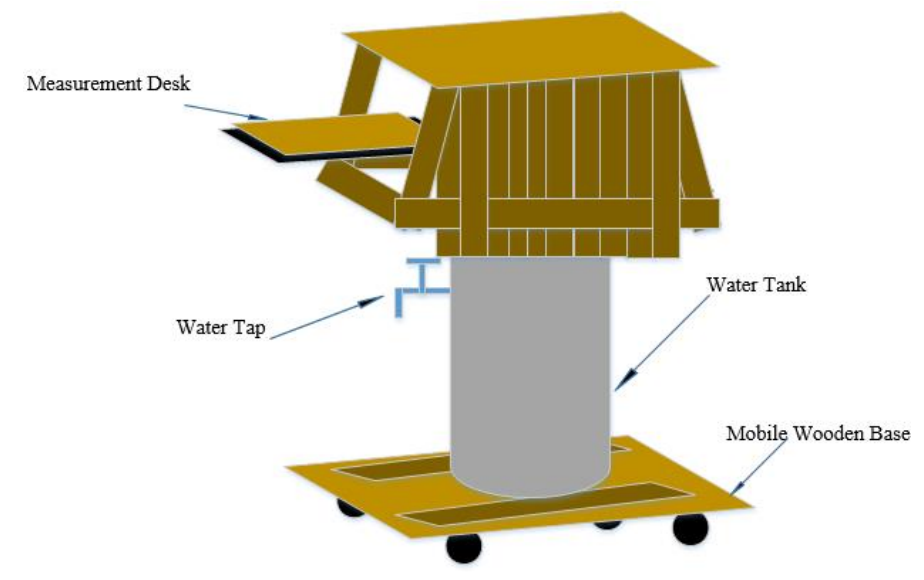

Figure 1 Mechanical design of the hydro power emulator

To one side of the truncated shape frame the microhydropower generators circuit is connected. It contains of a set of micro-hydropower generators, pressure gauge, water flow sensor and voltage regulator. The generators is fitted with U.K. certified $15 \mathrm{~mm}$ water pipes. A set of commercially available micro-hydropower generators with $1 / 2$ " water inlet/outlet which is suitable for domestic water pipes is shown in Figure 2 have been used. Experimental results proved that the optimum number of micro-hydro generators is 4 where a combination of two is connected in parallel $(2 \times 2)$. Figure 3 below shows the hydropower generators circuit.

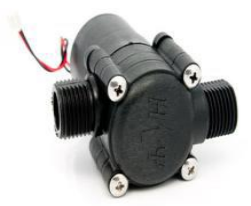

Figure 2 Micro-hydro generator $\sim 15 \mathrm{~V}$ 1watt

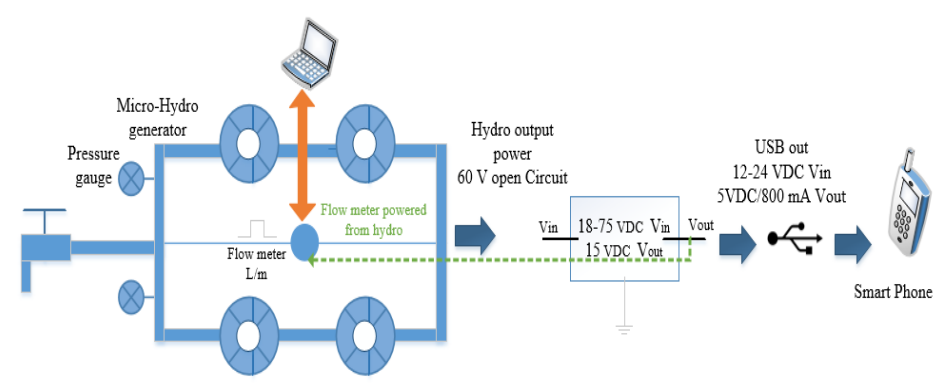

Figure 3 Block diagram of the micro-hydropower generators and measurements circuit

The water flow sensor is self-powered and digitally controlled through microcontroller to monitor the flow rate. The output of the micro-hydro generators is regulated by 18 75VDC/15VDC voltage regulator (TRACO TMR). The regulated output is then fed to $5 \mathrm{~V}$ USB output and used to charge a smart mobile phone. 


\section{SYSTEM OpERATION}

The complete hydropower emulator is constructed as aforementioned and shown in Figure 4.

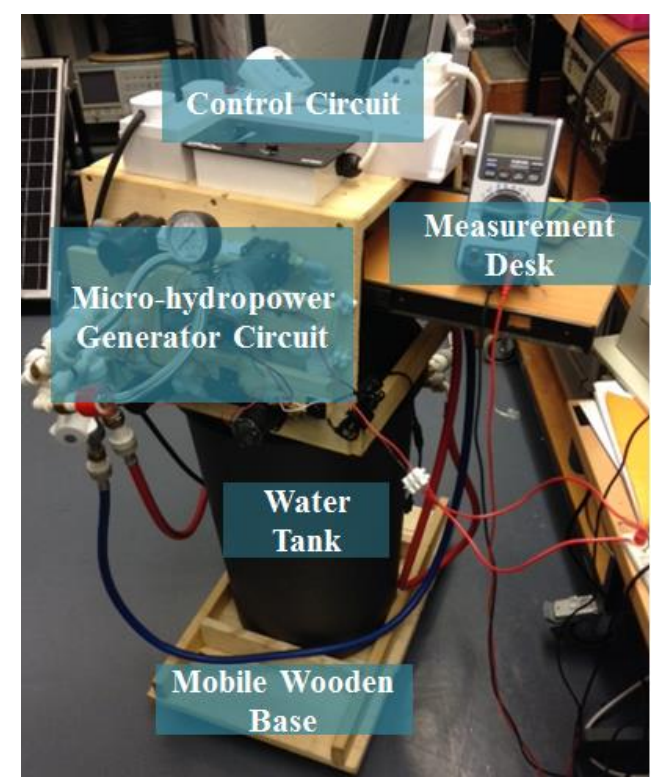

Figure 4 Hydropower emulator

The control circuit mounted on the top of the truncated wooden frame controls the operation of the hydro emulator. It incorporates a speed controller which controls the speed of water pump and hence the flow rate. This allows studying the operation of the generators at various flow rates. The electronic switch acts as a phase shifter and digitally controlled to emulate different loads (i.e. Household, hotel or university residence).

Thus, to operate the system, the main switching key is switched on which in turn turns the pump on. The speed of the pump can be set through the speed controller while the electronic switch is controlled through USB. As the water follows through the pipes the hydro generators the blades of the micro-hydros starts to rotate generating power. The output power is regulated using commercial voltage regulator.

\section{EXPERIMETAL RESULTS}

\section{A. Optimum Hydro Generators Configuration}

Experiential testing was carried out to find the optimum configuration for a U.K. domestic supply delivered through $15 \mathrm{~mm}$ pipe. The key concept is to use a set of microhydropower generators to improve the power generated from the domestic water tap. Two different configurations were tested; two serial/parallel and three serial/parallel. Figure 5 and Figure 6show the output power for the $2 \times 2$ and $3 \times 3$ sets respectively as a function of the resistance.

Using a set of two micro-hydropower generators in serial/parallel a maximum of nearly 4 watts into a $330 \mathrm{ohm}$ load is obtained. However, adding an extra set of two generators has hardly improved the output power, with maximum output power of 4.08 watts at $470 \mathrm{ohm}$.

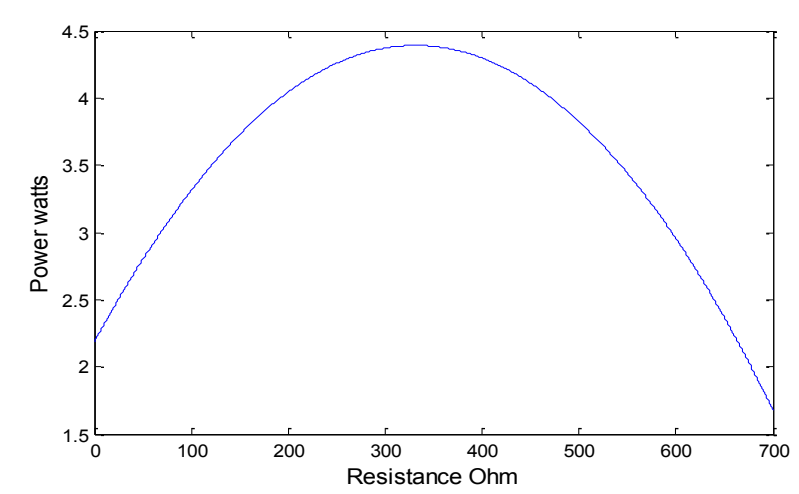

Figure 5 Hydropower output of the $2 \times 2$ micro hydropower generators

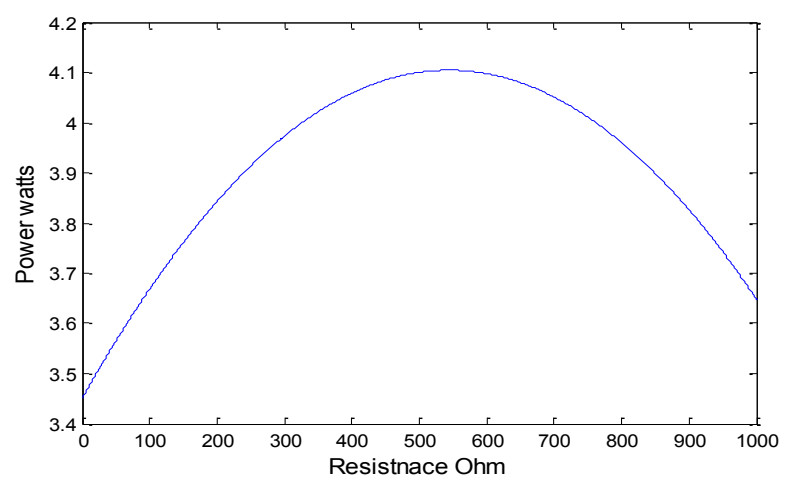

Figure 6 Hydropower output of the $3 \times 3$ micro hydropower generators

\section{B. Hydropower Output at Different Speeds}

The generated hydropower is directly related to the water flow rate. By varying the speed of the water pump the corresponding flow rate could be varied. This allows investigating the behavior of the hydro output power as a function of the flow rate. Figure 7 below, indicates the generated output power at different flow rate (12 liters/minute, 10 liters/minute and 6 liters/minute)

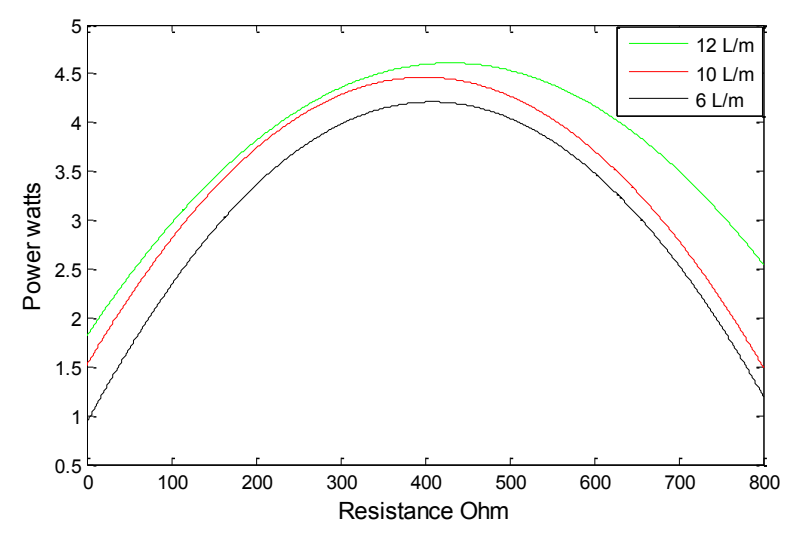

Figure 7 Hydropower generated at different flow rates

It is obvious from Figure 7 above that generated hydro power increases with increasing flow rate. It is also clear that moderate power is generated even at low flow rates. 


\section{ELECTRICAL OUTPUT}

When the aforementioned system was constructed, the key lies in using a set of hydro generators to enhance the output. At the maximum water force from a single tap and using four micro-hydro generators, power of 4 watts was obtained. From the power verses resistance curve it is obvious that the maximum power is 4 watts at the optimum load of $330 \mathrm{ohm}$. The open circuit voltage is 60 volts and as the tap water force decreases the output decays to nearly zero. Figure 8 below shows the output power as a function of the resistance

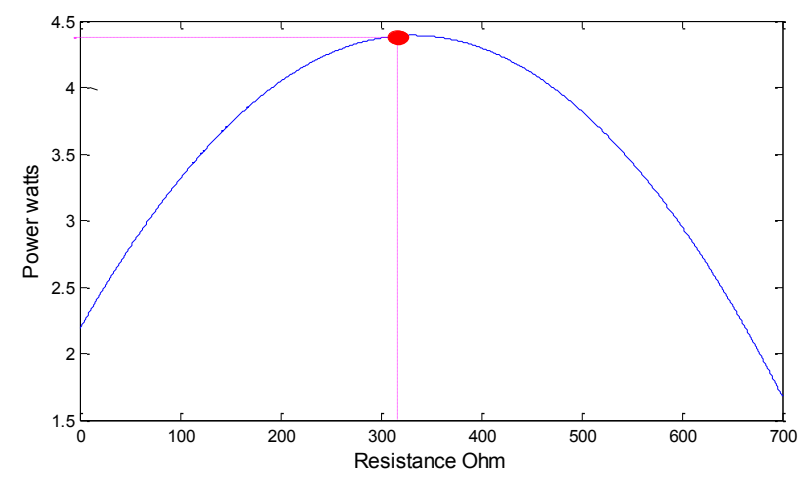

Figure 8 Output power Vs load resistance

The output power is regulated to $15 \mathrm{VDC}$ through a switched-mode voltage regulator and fed to 5V USB output. A power bank of $10000 \mathrm{mAh}$ capacity could be charged through $5 \mathrm{~V} / 800 \mathrm{~mA}$ USB output at nearly 12 hours. This power can then be used to charge any USB gadget.

\section{CASE STUdy}

This section investigates the relation between the water and electricity consumption in a residential environment. Most of the daily activity that takes place in household involves using electricity, example being: washing machine, dish washer and power shower. According to the U.K. water utility company Waterwise, as much as $30 \%$ of household water usage is consumed towards personal washing including baths and showers. Also, clothes washing and washing-up takes up nearly $20 \%$ of the household's daily water consumption. Given that hydropower generation is directly related to water consumption, a useful amount of power could be harnessed as the water is being consumed.

Thus, as well as relating residential water consumption to the power it involves in its operation, the potential hydropower that could be generated using the proposed micro-hydropower generator system is anticipated. The calculation considered in this section is mainly based on full-time working two occupiers household and the criteria illustrated in Table II.

(Criteria: Average water consumption for a house of two occupiers (101 m3 276 Liters per day), Four daily activity that involves means of electricity consumption, 24 hours study case)

The U.K. average water consumption for a house of two individuals is averaged considering that the washing machine and dishwasher is used most days as well daily baths or use of power showers. Table I shows in liters the amount of water consumed by individual for the investigated daily activity according to the Waterwise water utility company. Also, the average power consumption of the household appliances inspected in this study is tabulated in Table II.

TABLE I AVERAGE WATER USAGE IN LITER PER DAY FOR VARIOUS DAILY ACTIVITIES

\begin{tabular}{|l|l|}
\hline Daily activity & \multicolumn{1}{|c|}{ Average Water Usage } \\
\hline Shower & 75 liter per 5 minutes \\
\hline Washing Machine & 85 liters per load \\
\hline Dishwasher & 42 liters per load \\
\hline Food Preparation & 15 liters per occasion \\
\hline
\end{tabular}

TABLE II POWER CONSUMPTION OF THE INVESTIGATED APPLIANCES

\begin{tabular}{|l|c|}
\hline \multicolumn{1}{|c|}{ Appliance } & $\begin{array}{c}\text { Power Consumption } \\
\text { watts }\end{array}$ \\
\hline Power Shower & 750 \\
\hline Microwave Oven & 600 \\
\hline Kettle & 2000 \\
\hline Dishwasher & 1300 \\
\hline Washing Machine & 500 \\
\hline
\end{tabular}

The potential yield in $\mathrm{kWh}$ hour based on the operation time of the appliance and its electricity consumption is illustrated in Table III.

TABLE III ANALYSIS OF WATER AND ELECTRICITY CONSUMPTION AND THE POTENTIAL YIELD FOR THE INVESTIGATED SCENARIO

\begin{tabular}{|l|c|c|c|c|}
\hline \multicolumn{1}{|c|}{ Action } & $\begin{array}{c}\text { Time } \\
\text { Minutes }\end{array}$ & $\begin{array}{c}\text { Consumed } \\
\text { Water } \\
\mathrm{L}\end{array}$ & $\begin{array}{c}\text { Consumed } \\
\text { Electricity } \\
\mathrm{kWh}\end{array}$ & $\begin{array}{c}\text { Potential } \\
\text { Yield } \\
\mathrm{kWh}\end{array}$ \\
\hline Power Shower & 18 & 119 & 0.24 & 0.0012 \\
\hline Food Preparation & 16 & 45 & 4.75 & 0.0012 \\
\hline Dish Washer & 30 & 42 & 0.65 & 0.002 \\
\hline Washing Machine & 30 & 85 & 0.25 & 0.002 \\
\hline
\end{tabular}

It is obvious from the Table III that the potential yield from power shower, which makes up the highest water consumption, is $0.005 \%$ of the consumed power. It is also clear that as the time of the water consumption is increased the energy generated power increases as a result. It could be argued that it is a minute amount however such useful power is available but not harnessed. Also considering the fact that power is accumulative, power could be stored and used for low power home emergencies appliances. Also, increasing the generated power is a matter of scaling the system. 


\section{CONCLUSION}

In this paper, a review of the available domestic microhydropower generation systems has been summarized. An experimental evaluation system of micro-hydropower generator for professional formation and research has been proposed. The paper details the design and construction of the proposed system including the design optimization.

The paper investigated the water consumption for a scenario of two occupier household relative to the electricity consumption. It concludes that there is a useful potential hydropower relative to the water consumption which should not be a challenge for low power home emergencies appliances.

\section{REFERENCES}

[1] A. Chapagain. and S. Orr. "UK Water Footprint: the impact of the UK's food and fibre consumption on global water resources" WWF-UK. Vol.1, August. 2008.

[2] T. C. Yan, T. Ibrahim, and N. M. Nor, "Micro hydro generator applied on domestic pipeline," in Electrical Engineering and Informatics (ICEEI), 2011 International Conference on. pp. 1-6, 2011.

[3] Utility Regulation, "Water Services-2: DG2, DG3 and DG4," Annual information reporting requirement and definition manual, vol.1, pp. 122, March. 2011.

[4] R. and L. "In-line fluid-driven electric power generator." U.S. Patent No. 6,011,334. January, 4, 2000.

[5] N. and E. . "Pipeline deployed hydroelectric generator." U.S. Patent No. 7,723,860. May, 25, 2010.

[6] O. , L. , and S.Kevin. "Inline turbine generator." U.S. Patent Application 13/142,059, filed December 22, 2009.

[7] S. Lialitha. "Micro-Generation of Electricity from Tap Water" International Journal of Emerging Technology and Advanced Engineering, vol 3, no 10, 2013.

[8] D. Hoffmann, A. Willmann, R. Göpfert, P. Becker, B. Folkmer, and Y. Manoli. "Energv Harvesting from Fluid Flow in Water Pinelines for Smart Metering Applications." In Journal of Physics: Conference Series, vol. 476, no. 1, p. 012104. IOP Publishing, 2013.

[9] The Hong Kong Polytechnic University "Electricity from water mains: PolyU's novel inline hydropower system for power generation from water pipelines" Technology Frontier, Nov.2012.

[10] TOTO. "Green products: Eco Power Faucets," [Online] Available at : http://www.totousa.com/ Last accessed [ 10 September 2015].

[11] International Design Excellence Awards 2012, “ IDEA 2012 Finalist: Student Designs Winners"

[12] Waterwise, "Consumer Council for Water: Annual Report and Accounts 2014-2015" [Online] Available at http://www.ccwater.org.uk/publications/annualreportaccounts/ Last accessed [ 10 September 2015]. 